\title{
Analisis Kondisi Fisik Rumah Dan Karakteristik Responden Terhadap Kejadian Tuberkulosis Di Kecamatan Ciledug Kota Tangerang
}

\author{
*Heru Purwanto Nugroho' ${ }^{1)}$, Lilis Heri Mis Cicih ${ }^{1)}$, Sutanto Priyo Hastono ${ }^{1)}$
}

${ }^{1}$ Program Studi Magister Kesehatan Masyarakat Fakultas Kesehatan Universitas MH Thamrin

*Correspodence author: Heru Purwanto Nugroho, pnheru@ gmail.com, Tangerang,Indonesia

\begin{abstract}
Abstrak
Secara global Tuberkolusis tergolong sebagai global health emergency. Peningkatan kasus TB dari tahun 2015 - 2018. TB paru merupakan salah satu prioritas utama yang harus ditangani untuk mewujudkan Indonesia Sehat (RPJMN 2020 - 2024). Karakterisitik lingkungan merupakan kunci penentu kemungkinan penularan. Umur, jenis kelamin dan status gizi merupakan salah satu faktor yang menyebabkan terjadinya penyakit.

Menganalisis hubungan kondisi fisik rumah dan karakteristik responden terhadap kejadian TB. Mengetahui variabel yang berhubungan dan yang paling dominan terhadap kejadian TB.

Metode : Jenis penelitian observasional analitik dengan rancangan penelitian case control. Lokasi penelitian dilakukan di Kecamatan Ciledug Kota Tangerang.

Hasil penelitian pada kelompok kasus dan kontrol menunjukkan bahwa terdapat perbedaan yang signifikan pada kelembaban dan IMT. Hasil uji chi-square didapatkan $p$-value sebesar 0,028 dan $0,000(<0,05)$. Hasil analisis multivariat didapatkan hasil kelembaban dengan p-value 0,003 dengan OR 8,469 dan IMT dengan nilai $p$-value 0,000 dengan OR 14,940. IMT merupakan variabel yang paling dominan terhadap kejadian TB.

Melakukan kerjasama lintas sektoral antara Puskesmas dengan Kelurahan dalam rangka perbaikan status gizi pada penderita TB. Diharapkan kepada Dinas Kesehatan terkait untuk melakukan program promosi kesehatan tentang pencegahan dan pengendalian TB Paru kepada masyarakat.
\end{abstract}

Kata Kunci : TB paru, Status Gizi, IMT, Kelembaban, Kondisi fisik rumah

\section{Abstract}

Globally, Tuberculosis is classified as a global health emergency. Increased TB cases from 2015 2018. Pulmonary TB is one of the main priorities that must be addressed to achieve a Healthy Indonesia (RPJMN 2020-2024). Environmental characteristics are the key to determining the likelihood of transmission. Age, sex and nutritional status are among the factors that cause disease.

To analyze the relationship between the physical condition of the house and the characteristics of the respondents to the incidence of $T B$. Knowing the variables that are related and the most dominant to the incidence of $T B$.

This was an analytic observational study with a case control study design. The research location was conducted in Ciledug District, Tangerang City.The results of the study in the case and control groups showed that there were significant differences in humidity and BMI. Chi-square test results obtained p-values of 0.028 and $0.000(<0.05)$. The results of the multivariate analysis showed that the humidity results with a p-value of 0.003 with an OR of 8.469 and a BMI with a p-value of 0.000 with an OR of 14.940. BMI is the most dominant variable in the incidence of $T B$.

Carry out cross-sectoral cooperation between Puskesmas and Kelurahan in order to improve the nutritional status of TB patients. It is hoped that the relevant health office will carry out health promotion programs on the prevention and control of pulmonary tuberculosis to the public.

Keywords: pulmonary tuberculosis, nutritional status, BMI, humidity, physical condition of the house

Open Journal System (OJS): journal.thamrin.ac.id

http://journal.thamrin.ac.id/index.php/anakes/issue/view/43 


\section{PENDAHULUAN}

Secara global Tuberkolusis tergolong sebagai global health emergency. Penyakit tuberculosis sampai saat ini masih menjadi permasalahan kesehatan masyarakat di beberapa negara termasuk Indonesia, prevalensinya menempati urutan ketiga negara dengan kasus tuberkulosis tertinggi di dunia. Negara dengan kasus terbanyak di dunia adalah India dan China menempati urutan kedua (WHO, 2017).

World Health Organization (WHO) mendeklarasikan bahwa penyakit tuberkulosis harus segera dieliminasi pada tahun 2030 (WHO, 2015). Sama halnya dengan di Indonesia, Kementerian Kesehatan Republik Indonesia (Kemenkes RI) juga menargetkan bahwa Indonesia harus bebas dari tuberkulosis pada tahun 2030 (Kemenkes RI, 2017). Berdasarkan hal tersebut, tuberkulosis masih menjadi prioritas utama dalam penindaklanjutan program Sustainable Development Goals (SDGs) dalam bidang kesehatan Rencana Pembangunan Jangka Menengah Nasional (RPJMN) 2020-2024, TB paru menjadi salah satu prioritas utama yang harus ditangani untuk mewujudkan Indonesia Sehat.

Berdasarkan data Riset Kesehatan Dasar (RISKESDAS) tahun 2018, Provinsi Banten dan Papua merupakan provinsi dengan kasus TB terbanyak di Indonesia. Menurut data profil kesehatan Provinsi Banten pada tahun 2016, penyakit Tuberkulosis paru terbanyak berada di wilayah Kabupaten Tangerang, Kabupaten Serang, dan Kota Tangerang. Dari ketiga wilayah tersebut Kota Tangerang merupakan daerah terpadat dengan rata-rata jumlah populasi per $\mathrm{km}^{2}$ sebanyak 22.628 jiwa (BPS Kota Tangerang, 2019). Badan Pusat Statistik Kota Tangerang tahun 2020 menyatakan bahwa Kecamatan Ciledug Kota Tangerang memiliki populasi penduduk terpadat di Kota Tangerang yaitu 23.305 orang $/ \mathrm{km}^{2}$. Kasus Tuberkulosis di Kecamatan Ciledug Kota Tangerang mengalami peningkatan dari tahun 2015 sampai 2018 (Profil Dinas Kesehatan Kota Tangerang, 2017).

Dalam perspektif epidemiologi yang melihat kejadian penyakit sebagai hasil interaksi antar tiga komponen pejamu (host), penyebab (agent), dan lingkungan (environment) dapat ditelaah faktor risiko dari simpul-simpul tersebut (Riskesdas, 2018). Karakterisitik 
lingkungan merupakan kunci penentu kemungkinan penularan. Penularan di luar ruangan (outdoor) sangatlah kecil dibandingkan dengan penularan di dalam ruangan (indoor) (Erkens et.al, 2010). Faktor-faktor yang dapat menimbulkan penyakit pada penjamu terdiri dari umur, jenis kelamin dan status gizi. (Kunoli, 2013).

Berdasarkan hal tersebut perlu dianalisis kondisi fisik rumah dan karakteristik responden terhadap kejadian TB Paru di Kota Tangerang khususnya di Kecamatan Ciledug Kota Tangerang. Kondisi fisik rumah dan karakteristik responden yang bagaimana yang mempengaruhi kejadian TB di Kota Tangerang.

\section{METODE PELAKSANAAN}

Jenis penelitian ini merupakan penelitian observasional analitik dengan rancangan penelitian case control. Lokasi penelitian dilakukan di Kecamatan Ciledug Kota Tangerang (wilayah kerja Puskesmas Paninggilan dan Tajur). Waktu penelitian di lakukan pada bulan September dan Oktober tahun 2020. Populasi yang digunakan dalam penelitian ini adalah semua rumah yang ada di wilayah kerja Puskesmas Tajur dan Paninggilan Kecamatan Ciledug Kota Tangerang. Sampel kasus adalah rumah pasien yang didiagnosa TB paru dan datanya terdaftar dalam SITB bulan November-Desember 2019 dan Januari-Oktober 2020. Rumah warga yang menjadi kontrol merupakan tetangga dari rumah pasien TB. Dengan pertimbangan peneliti bahwa kontrol berasal dari rumah warga yang belum pernah dilaporkan ada kasus TB diharapkan memiliki kondisi lingkungan yang berbeda dengan kasus, sehingga dapat dianalisis.

Teknik pengambilan sampel dalam penelitian ini adalah purposive sampling. Data yang dikumpulkan dalam penelitian ini terdiri dari data primer yang berasal dari beberapa sumber yang dikumpulkan pada bulan September sampai Oktober 2020. Analisis data menggunakan perangkat pengolah data yang dilakukan secara bertahap yaitu univariat, bivariat, dan multivariat Setelah data di analisa maka informasi disajikan dalam bentuk table distribusi frekwensi dan gambar serta narasi.

\section{HASIL DAN PEMBAHASAN}

Open Journal System (OJS): journal.thamrin.ac.id 100 http://journal.thamrin.ac.id/index.php/anakes/issue/view/43 
Jumlah responden penelitian yaitu sebanyak 100 orang, yang terdiri dari 50 kasus dan 50 kontrol dengan perbandingan 1 kasus 1 kontrol. Sebaran penderita TB paru pada wilayah kerja Puskesmas Tajur dan Puskesmas Paninggilan dapat dilihat pada Gambar 1 berikut ini:

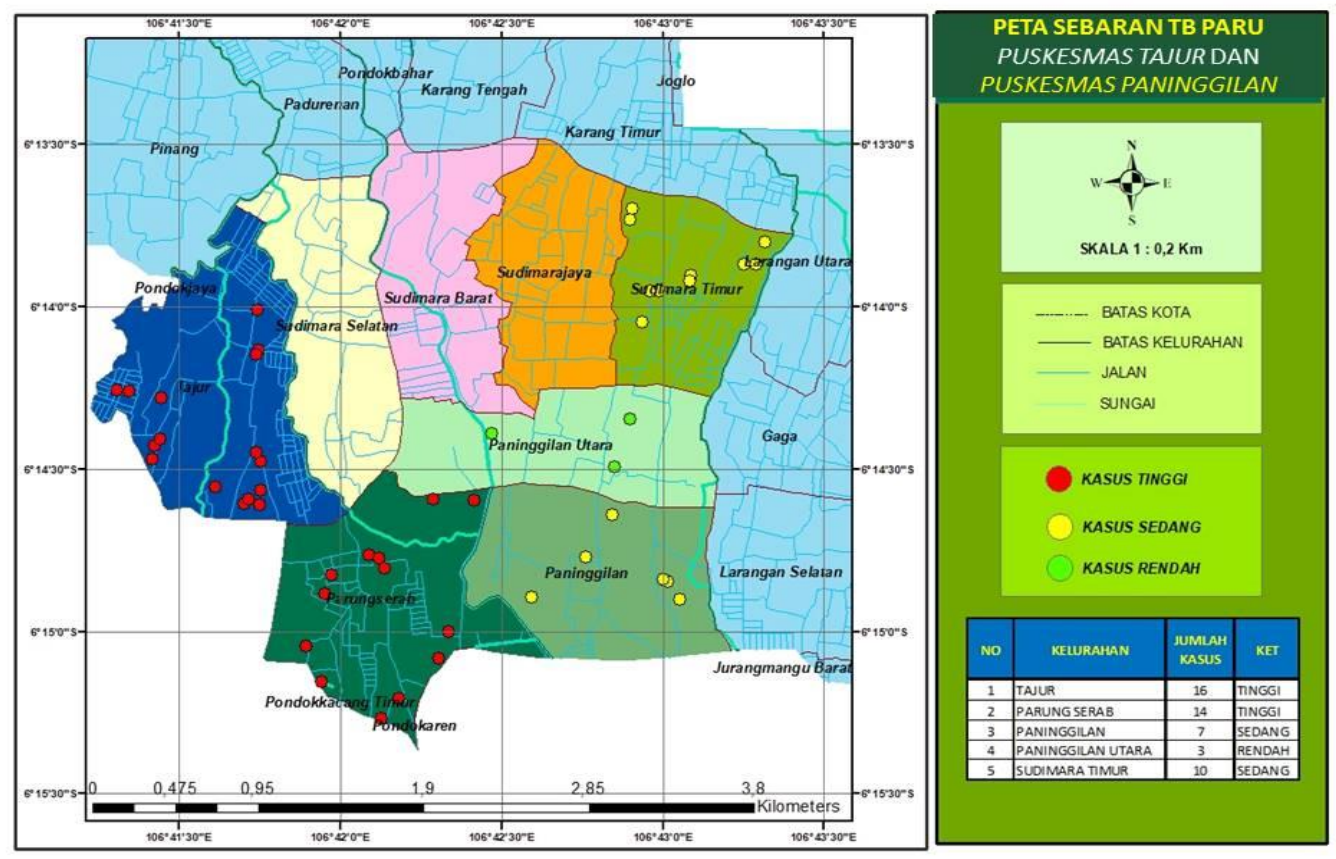

Gambar 1

Peta Sebaran TB di Puskesmas Tajur dan Puskesmas Paninggilan Kecamatan Ciledug Kota Tangerang

\section{Analisis Univariat}

Variabel yang termasuk dalam karakteristik responden yaitu umur, jenis kelamin, status gizi (IMT), status bekerja dan pendidikan. Hasil dari Penelitian terhadap variabel ini terlihat dalam Tabel 1.

Tabel 1

Distribusi Frekuensi Responden Menurut Karakteristik di Wilayah Kerja Puskesmas Tajur dan Puskesmas Paninggilan, Tahun 2020.

\begin{tabular}{|c|c|c|c|c|}
\hline \multirow{3}{*}{ Variabel } & \multicolumn{4}{|c|}{ Responden } \\
\hline & \multicolumn{2}{|c|}{ Kasus } & \multicolumn{2}{|c|}{ Kontrol } \\
\hline & $\mathrm{n}$ & $\%$ & $\mathrm{n}$ & $\%$ \\
\hline \multicolumn{5}{|l|}{ Umur } \\
\hline 15-19 tahun & 2 & 25 & 6 & 75 \\
\hline $\begin{array}{l}20 \text { - } 64 \text { tahun } \\
\text { Jenis Kelamin }\end{array}$ & 48 & 52 & 44 & 48 \\
\hline
\end{tabular}

Open Journal System (OJS): journal.thamrin.ac.id 


\begin{tabular}{|c|c|c|c|c|}
\hline Perempuan & 20 & 51 & 19 & 49 \\
\hline Laki-laki & 30 & 49 & 31 & 51 \\
\hline \multicolumn{5}{|l|}{ IMT } \\
\hline Normal & 47 & 64 & 26 & 36 \\
\hline Kurang & 3 & 11 & 24 & 89 \\
\hline \multicolumn{5}{|l|}{ Status Bekerja } \\
\hline Bekerja & 27 & 48 & 29 & 52 \\
\hline Tidak Bekerja & 23 & 52 & 21 & 48 \\
\hline \multicolumn{5}{|l|}{ Pendidikan } \\
\hline Tinggi ( $\geq$ SMA) & 38 & 49 & 39 & 51 \\
\hline Rendah $(\leq \mathrm{SMP})$ & 12 & 52 & 11 & 48 \\
\hline
\end{tabular}

Pada tabel 1 disajikan hasil uji univariat karakteristik responden baik kasus maupun kontrol. Persentasi tertinggi proporsi pada kelompok kasus terletak pada IMT dengan katagori normal 64\% dan usia 20-64 tahun 52\%. Sedangkan Persentasi tertinggi proporsi pada kelompok kontrol adalah IMT katagori kurang 89\% dan usia 15-19 tahun 75\%.

Hasil pengukuran lingkungan fisik rumah yang diperoleh adalah seperti pada Tabel 2.

Tabel 2

Distribusi Frekuensi Responden Menurut Lingkungan Fisik Rumah di Kecamatan Ciledug Kota Tangerang, Tahun 2020

\begin{tabular}{|c|c|c|c|c|}
\hline \multirow{3}{*}{ Variabel } & \multicolumn{4}{|c|}{ Responden } \\
\hline & \multicolumn{2}{|c|}{ Kasus } & \multicolumn{2}{|c|}{ Kontrol } \\
\hline & $\mathrm{n}$ & $\%$ & $\mathrm{n}$ & $\%$ \\
\hline \multicolumn{5}{|l|}{ Suhu } \\
\hline Memenuhi syarat & 47 & 52 & 43 & 48 \\
\hline $\begin{array}{l}\text { Tidak memenuhi syarat } \\
\text { Ventilasi }\end{array}$ & 3 & 30 & 7 & 70 \\
\hline Memenuhi syarat & 46 & 52 & 42 & 48 \\
\hline $\begin{array}{l}\text { Tidak memenuhi syarat } \\
\text { Kepadatan }\end{array}$ & 4 & 33 & 8 & 67 \\
\hline Memenuhi syarat & 45 & 53 & 40 & 47 \\
\hline $\begin{array}{l}\text { Tidak memenuhi syarat } \\
\text { Kelembaban }\end{array}$ & 5 & 33 & 10 & 67 \\
\hline Memenuhi syarat & 47 & 59 & 33 & 41 \\
\hline $\begin{array}{l}\text { Tidak memenuhi syarat } \\
\text { Pencahayaan }\end{array}$ & 3 & 15 & 17 & 85 \\
\hline Memenuhi syarat & 47 & 55 & 38 & 45 \\
\hline $\begin{array}{l}\text { Tidak memenuhi syarat } \\
\text { Jenis Lantai }\end{array}$ & 3 & 20 & 12 & 80 \\
\hline Memenuhi syarat & 50 & 100 & 50 & 100 \\
\hline Tidak memenuhi syarat & 0 & 0 & 0 & 0 \\
\hline
\end{tabular}




\begin{tabular}{lcccc} 
Jenis Dinding & & & & \\
Memenuhi syarat & 50 & 100 & 50 & 100 \\
Tidak memenuhi syarat & 0 & 0 & 0 & 0 \\
\hline \hline
\end{tabular}

Berdasarkan uji univariat pada penelitian ini didapatkan hasil faktor kondisi fisik rumah pada Tabel 2. Variabel jenis lantai dan jenis dinding didapatkan $100 \%$ memenuhi syarat. Kondisi fisik rumah baik suhu, kelembaban, kepadatan, pencahayaan dan ventilasi responden ratarata sudah memenuhi syarat. Dari Tabel 2 diperoleh persentasi yang tertinggi proporsi pada kelompok kasus terletak pada kelembaban yang memenuhi syarat sebesar 59\%, dan pencahayaan yang memenuhi syarat 55\%. Pada kelompok kontrol, proporsi antara suhu, ventilasi, kepadatan, kelembaban dan pencahayaan hampir sama.

\section{Analisis Bivariat}

Pada analisis bivariat didapatkan variabel yang berhubungan dengan kejadian TB paru di Kecamatan Ciledug Kota Tangerang adalah kelembaban dan status gizi (IMT). Hal ini dikarenakan kelembaban mempunyai $p$-value $=0.028$ dan IMT mempunyai $p$-value $=0.000$, $(p$-value $<0.05)$. Hal ini dapat dilihat pada Tabel 3 .

Tabel 3

Hubungan Faktor Kondisi Fisik Rumah dan Faktor Karakteristik Responden Terhadap Kejadian TB Paru di Wilayah Kerja Puskesmas Tajur dan Puskesmas Paninggilan Tahun 2020

\begin{tabular}{|c|c|c|c|c|c|c|}
\hline \multirow{3}{*}{ Variabel } & \multicolumn{4}{|c|}{ Responden } & \multirow{3}{*}{$\begin{array}{c}\text { OR } \\
(95 \% \mathrm{CI})\end{array}$} & \multirow{3}{*}{ P-Value } \\
\hline & \multicolumn{2}{|c|}{ Kasus } & \multicolumn{2}{|c|}{ Kontrol } & & \\
\hline & $\mathrm{n}$ & $\%$ & $\mathrm{n}$ & $\%$ & & \\
\hline \multicolumn{7}{|l|}{ Suhu } \\
\hline Memenuhi syarat & 47 & 52 & 43 & 48 & 1.9 & \multirow{2}{*}{0.539} \\
\hline $\begin{array}{l}\text { Tidak memenuhi syarat } \\
\text { Ventilasi }\end{array}$ & 3 & 30 & 7 & 70 & $(0.245-14.730)$ & \\
\hline Memenuhi syarat & 46 & 52 & 42 & 48 & 0.355 & \multirow{2}{*}{0.333} \\
\hline $\begin{array}{l}\text { Tidak memenuhi syarat } \\
\text { Kepadatan }\end{array}$ & 4 & 33 & 8 & 67 & $(0.044-2.894)$ & \\
\hline Memenuhi syarat & 45 & 53 & 40 & 47 & 1.082 & \multirow{2}{*}{0.921} \\
\hline $\begin{array}{l}\text { Tidak memenuhi syarat } \\
\text { Kelembaban }\end{array}$ & 5 & 33 & 10 & 67 & $(0.229-5.113)$ & \\
\hline Memenuhi syarat & 47 & 59 & 33 & 41 & 7.503 & \multirow{2}{*}{$0.028 *$} \\
\hline Tidak memenuhi syarat & 3 & 15 & 17 & 85 & $(1.245-45.208)$ & \\
\hline
\end{tabular}

Open Journal System (OJS): journal.thamrin.ac.id 


\begin{tabular}{|c|c|c|c|c|c|c|}
\hline \multicolumn{7}{|l|}{ Pencahayaan } \\
\hline Memenuhi syarat & 47 & 55 & 38 & 45 & 1.466 & \multirow{2}{*}{0.697} \\
\hline Tidak memenuhi syarat & 3 & 20 & 12 & 80 & $(0.214-10.016)$ & \\
\hline \multicolumn{7}{|l|}{ Umur } \\
\hline 11-19 tahun & 2 & 25 & 6 & 75 & 0.706 & \multirow{2}{*}{0.775} \\
\hline $20-60$ tahun & 48 & 52 & 44 & 48 & $(0.065-7692)$ & \\
\hline \multicolumn{7}{|l|}{ Jenis Kelamin } \\
\hline Perempuan & 20 & 51 & 19 & 49 & 0.449 & \multirow{2}{*}{0.252} \\
\hline Laki-laki & 30 & 49 & 31 & 51 & $(0.114-1.766)$ & \\
\hline \multicolumn{7}{|l|}{ IMT } \\
\hline Normal & 47 & 64 & 26 & 36 & 17.437 & \multirow{2}{*}{$0.000^{*}$} \\
\hline Kurang & 3 & 11 & 24 & 89 & $(4.039-75.281)$ & \\
\hline \multicolumn{7}{|l|}{ Status Bekerja } \\
\hline Bekerja & 27 & 48 & 29 & 52 & 0.477 & \multirow{2}{*}{0.302} \\
\hline Tidak Bekerja & 23 & 52 & 21 & 48 & $(0.117-1.947)$ & \\
\hline \multicolumn{7}{|l|}{ Pendidikan } \\
\hline Tinggi ( $\geq$ SMA) & 38 & 49 & 39 & 51 & 0.749 & \multirow{2}{*}{0.653} \\
\hline Rendah ( $\leq \mathrm{SMP})$ & 12 & 52 & 11 & 48 & $(0.212-2.643)$ & \\
\hline
\end{tabular}

pada variabel suhu hasil penelitian menunjukan bahwa tidak ada hubungan suhu dengan kejadian TB paru di Kecamatan Ciedug ( $p$-value $=0,539$ ), dimana proporsi suhu yang tidak memenuhi syarat pada kelompok kasus (30\%) lebih rendah dibandingkan kelompok kontrol $(70 \%)$. Variabel ventilasi pada analisis bivariat tidak memepunyai hubungan dengan kejadian TB paru di Kecamatan Ciledug, hal ini dapat dilihat dari nilai $p$-value $=0,333$ ( $>$ $0,05)$. Variabel kepadatan tidak ada hubungannya dengan kejadian TB paru pada penelitian ini $(p$-value $=0,921>0,05)$. Hasil analisis statistik menggunakan uji chi square pada kelembaban rumah diperoleh nilai $p$-value $=0.028$, maka dapat disimpulkan secara statistik terdapat hubungan yang signifikan antara kelembaban dengan kejadian TB paru di Kecamatan Ciledug Kota Tangerang. Dari data diperoleh juga nilai OR sebesar 7,503 yang artinya kelembaban yang tidak memenuhi syarat beresiko 7 kali terhadap kejadian TB paru di Kecamatan Ciledug Kota Tangerang.

Karakteristik pada analisis bivariat didapatkan hasil proporsi umur 20-64 tahun sebesar 48\% lebih tinggi dari umur 15-19 tahun (2\%) pada kelompok kasus. Hasil menunjukan tidak ada hubungan antara umur dengan kejadian TB paru $p$-value $=0,775(>0,05)$. Variabel jenis kelamin tidak berhubungan dengan kejadian TB paru pada penelitian ini berdasarkan uji bivariat $(p$-value $=0,252>0,05$ ). Status gizi yang digambarkan oleh IMT mempunyai 
hubungan dengan kejadian TB paru di wilayah kerja Puskesmas Tajur dan Paninggilan Kecamatan Ciledug Kota Tangerang. Hal ini dapat dilihat dari hasil uji chi square diperoleh nilai $p$-value $=0.000,(p$-value $>0.05)$. IMT katagori kurang mempunyai peluang 17,437 terhadap kejadian TB di wilayah kerja Puskesmas Tajur dan Paninggilan, ini terlihat dari nilai OR sebesar 17.437. Variabel status bekerja dan pendidikan tidak mempunyai hubungan dengan kejadian TB paru, hal ini dapat dilihat dari nilai $p$-value $=0.302$ dan 0,653.

\section{Analisis Multivariat}

Hasil yang didapatkan pada pemodelan multivariat dapat dilihat pada tabel 4 di bawah ini

Tabel 4

Hasil Multivariat Variabel yang Berhubungan Signifikan dengan Kejadian TB paru di Kecamatan Ciledug Kota Tangerang Tahun 2020

\begin{tabular}{ccccc}
\hline \hline Variabel & $\mathrm{B}$ & $P$-Value & OR & $95 \% \mathrm{CI}$ \\
\hline Kelembaban & 2.136 & $0.003 *$ & 8.469 & $2.110-33.995$ \\
IMT & 2.704 & $0.000^{*}$ & 14.94 & $3.941-56.637$ \\
\hline \hline
\end{tabular}

Dari hasil analisis multivariat variabel kondisi fisik rumah yang mempengaruhi kejadian TB Paru di Kecamatan Ciledug Kota Tangerang Tahun 2020 adalah variabel kelembaban rumah. Hasil analisis didapatkan nilai Odds Ratio (OR) kelembaban sebesar 8.469, yang artinya kelembaban yang tidak memenuhi syarat berpeluang 8.469 kali terhadap kejadian TB paru di Kecamatan Ciledug Kota Tangerang tahun 2020 bila dibandingkan dengan rumah yang memiliki kelembaban yang memenuhi syarat. Variabel status gizi (IMT) yang kurang merupakan faktor yang yang paling dominan mempengaruhi Kejadian TB di Kecamatan Ciledug Kota Tangerang, berdasarkan uji statistik. Odds Ratio (OR) dari IMT adalah 14.940 yang artinya IMT yang kurang berpeluang 15 kali terhadap kejadian TB paru di Kecamatan Ciledug Kota Tangerang, bila dibandingkan dengan IMT yang normal.

\section{Faktor yang Berhubungan dengan Kejadian Tuberkulosis}

Berdasarkan analisis multivariat, variabel yang terbukti merupakan faktor risiko terhadap kejadian tuberkulosis adalah kelembaban.

Hubungan antara variabel kelembaban terhadap kejadian tuberkulosis diperoleh nilai $P$ Value $=0,003<0,05$. Hal ini bearti bahwa ada hubungan antara kelembaban terhadap 
kejadian tuberkulosis di Kecamatan Ciledug Kota Tangerang. Nilai OR kelembaban adalah 8,469 , hal ini berarti kelembaban rumah yang tidak memenuhi syarat mempunyai nilai resiko 8,5 kali terhadap kejadian TB paru di wilayah Kecamatan Ciledug Kota Tangerang bila dibandingkan dengan kelembaban yang memenuhi sayrat.

Hal ini didukung ketika peneliti melakukan pengukuran pada kelembaban rumah responden penderita TB Paru (kasus). Ada beberapa rumah yang kelembabannya masih kurang memenuhi syarat. Kondisi ini dipengaruhi lubang angin atau ventilasi yang ada pada rumah jarang dibuka. Jarak antara rumah yang satu dengan yang lain rapat, dan juga ada kendaraan yang parkir di area rumah. Dalam hal ini juga dapat dilihat dari distribusi frekuensi yaitu sebanyak 17 (85\%) kelembaban rumah tidak memenuhi syarat. Kelembaban yang memenuhi syarat yaitu ( $\geq 40 \%$ - $\leq 60 \%)$, sedangkan kelembaban yang tidak memenuhi syarat yaitu (< $40 \%->60 \%)$.

Penelitian ini sejalan dengan Anggreani dkk (2015) di Kabupaten Malang, terdapat hubungan yang bermakna antara kelembaban dengan kejadian TB Paru. Diah (2019) di Surabaya menyatakan rumah dengan kelembaban yang tidak memenuhi syarat akan mempengaruhi penghuninya untuk terkena TB paru sebanyak 4,792 kali dibandingkan rumah dengan kelembaban yang memenuhi syarat. Hal ini karena dinding dan langit-langit rumah responden beberapa diantaranya terdapat rembesan air dan berjamur. Kondisi dapat mengakibatkan bertahannya bakteri Mycobacterium tuberculosis di udara

Hasil penelitian ini berbeda dengan penelitan yang dilakukan Amalia (2015), yang menyatakan bahwa Kelembaban, tidak ada hubungan antara kelembaban dengan kejadian TB paru. Kelembaban udara rumah adalah kadar air rata - rata yang ada di dalam rumah. Menurut Permenkes RI No.1077/Menkes/Per/V/2011 tentang Pedoman Penyehatan Udara dalam ruang bahwa kelembaban udara yang memenuhi syarat adalah 40\%-60\%. Kelembaban udara yang tidak memenuhi syarat dapat menyebabkan pertumbuhan mikroorganisme yang mengakibatkan gangguan terhadap kesehatan manusia. Aliran udara yang lancar dapat mengurangi kelembaban dalam ruangan. Kelembaban yang tinggi merupakan media yang baik untuk bakteri-bakteri patogen penyebab penyakit.

\section{Faktor yang paling Dominan dengan Kejadian Tuberkulosis}


Berdasarkan analisis multivariat hasil yang paling dominan adalah status gizi yang digambarkan dengan IMT. Status gizi adalah salah satu faktor terpenting dalam pertahanan tubuh terhadap infeksi. Pada keadaan gizi yang buruk, maka reaksi kekebalan tubuh akan melemah, sehingga kemampuan dalam mempertahankan diri terhadap infeksi menjadi menurun. Status gizi yang kurang dapat menyebabkan lemahnya daya imun (sistem kekebalan tubuh) dalam mempertahankan diri dari suatu penyakit termasuk TB (Binongko, 2012).

Berdasarkan analisis bivariat didapatkan $P$-Value $=0.000$ yang bearti bahwa ada hubungan IMT dengan kejadian TB paru di wilayah Kecamatan Ciledug Kota Tangerang. Berdasarkan analisis multivariat menggunakan uji regresi logistik untuk mengetahui variabel manakah yang paling berhubungan, maka diperoleh variabel IMT mempunyai nilai $\mathrm{P}=0.000$ dan $\mathrm{OR}$ = 14.940, yang artinya status gizi yang digambarkan oleh IMT dengan katagori kurus sangat berhubungan dan mempunyai peluang 15 kali terhadap kejadian TB Paru di wilayah Kecamatan Ciledug Kota Tangerang.

Penelitian ini sejalan dengan Rahmi (2018) di Sumatra Barat, terdapat hubungan IMT dengan kejadian TB Paru. Isma dkk (2018) di Kebumen menyatakan adanya hubungan yang bermakna antara status gizi dengan kejadian Tuberkulosis paru dengan nilai $\mathrm{OR}=3,484$ (CI= 1,246 - 9,747) yang berarti status gizi kurang beresiko menderita Tuberkulosis paru sebesar 3,5 kali dibandingkan dengan status gizi cukup. Penelitian ini tidak sejalan dengan Dwi et all (2018) di Sulawesi Selatan yang menyatakan bahwa tidak ada hubungan antara status gizi dengan kejadian TB Paru. Hasil analisis besar risiko didapatkan nilai Odds Ratio $(\mathrm{OR})=0,345$ dan nilai $p$-value $=0,144$ ( $p$-value $>0,05)$.

Berdasarkan distribusi frekuensi IMT katagori kurus pada kasus sebesar 88.9\% yang artinya sebagian besar (hampir semua) pasien TB Paru di Kecamatan Ciledug Kota Tangerang tahun 2020 memiliki status gizi yang kurang. Hal ini dikarenakan kurangnya pengetahuan pasien TB terhadap pola makan sehat untuk mencapai status gizi yang baik. Hal ini bisa terjadi jika seseorang terserang penyakit, maka daya tahan tubuhnya akan menurun. Keadaan yang seperti ini berimbas pada penurunan nafsu makan, yang jika dibiarkan berlarut-larut akan terjadi penurunan berat badan sehingga jatuh pada status gizi kurus. Orang yang dengan status gizi kurus akan mudah terserang suatu penyakit, karena kekebalan tubuh menurun 
maka tubuh mudah terinfeksi suatu penyakit, tapi tidak semua orang kurus terserang penyakit dikarenakan sistim imun dalam tubuhnya masih bagus atau kuat. Status gizi yang buruk mengganggu system imun yang diperantarai Limfosit-T. Hal itu memudahkan terjadinya penyakit infeksi termasuk TB paru (Cegielski, 2012).

\section{SIMPULAN}

Dari hasil penelitian kondisi fisik rumah dan karakteristik responden, variabel yang berhubungan dengan kejadian TB paru di Kecamatan Ciledug Kota Tangerang adalah kelembaban dan IMT. Variabel yang tidak berhubungan dengan kejadian TB paru di Kecamatan Ciledug Kota Tangerang adalah suhu, ventilasi, kepadatan, pencahayaan, umur, jenis kelamin, status bekerja, dan pendidikan. Berdasarkan hasil uji statistik didapatkan variabel yang paling dominan terhadap kejadian TB paru di Kecamatan Ciledug Kota Tangerang adalah IMT.

Perlu adanya penyuluhan dan sosialisasi oleh petugas promosi kesehatan dan gizi untuk lebih aktif dalam meningkatan komunikasi, informasi dan edukasi (KIE) tentang gaya hidup sehat salah satunya pola makan sehat agar mencapai status gizi yang baik pada penderita TB. Melakukan kerjasama lintas sektoral antara Puskesmas dengan Kelurahan dalam rangka perbaikan status gizi pada penderita TB paru. Mengadakan kunjungan lapangan di luar gedung dari rumah ke rumah untuk mengaktifkan kegiatan klinik sanitasi sambil memberikan edukasi kepada masyarakat penyuluhan tentang lingkungan perumahan yang memenuhi syarat kesehatan kepada penduduk setempat agar dapat meningkatkan pengetahuan tentang TB paru dan dapat meningkatkan terjadinya perilaku hidup bersih dan sehat. Memberikan saran kepada Puskesmas untuk penyuluhan bidang kesehatan khususnya upaya pencegahan penyakit TB Paru. Diharapkan kepada Dinas Kesehatan terkait untuk melakukan program promosi kesehatan seperti kegiatan penyuluhan dan pemberian leaflet tentang pencegahan dan pengendalian TB Paru kepada masyarakat.

\section{REFERENSI}


Anggraeni, Saffira Kusuma, Mursid Raharjo, Nurjazuli. 2015, Hubungan Kualitas Fisik Rumah dan Perilaku Kesehatan dengan Kejadian TB Paru Di Wilayah Kerja Puskesmas Gondanglegi Kecamatan Gondanglegi Kabupaten Malang. Jurnal Kesehatan Masyarakat.

Amalia Kartika Syafri, 2015, Hubungan Kondisi Fisik Rumah Dengan Kejadian Tuberkulosis Paru Di Wilayah Kerja Puskesmas Ngemplak Boyolali, Naskah Publikasi, Program Studi Kesehatan Masyarakat Fakultas Ilmu Kesehatan Universitas Muhammadiyah Surakarta.

Binongko, Andhien 2012, Laporan Surveilance Epidemiologi Penyakit Tuberkulosis Di Puskesmas Wajo Kota Baubau.

BPS Kota Tangerang, 2020, Indikator Kesejahteraan Rakyat Kota Tangerang 2019

Cegielski P, Arab L, Cornoni-Huntl J, 2012, Nutritional Risk Factors for Tuberculosis Among Adults in the United States 1971-1992. American Journal of Epidemiology.

Dwi Santy Damayati, Andi Susilawaty, Maqfirah, 2018, Risiko Kejadian TB Paru di Wilayah Kerja Puskesmas Liukang Tupabbiring Kabupaten Pangkep, Jurnal hygiene.

Diah Dwi Lestari Muslimah, 2019, Keadaan Lingkungan Fisik Dan Dampaknya Pada Keberadaan Mycobacterium Tuberculosis: Studi Di Wilayah Kerja Puskesmas Perak Timur Surabaya, Jurnal Kesehatan Lingkungan.

Dinas Kesehatan Kota Tangerang, 2017, Profil Kesehatan P2M

Dinas Kesehatan Propinsi Banten, 2016, Profil Kesehatan Propinsi Banten.

Erkens CGM, Kamphorst M,Abubakar I, et al. 2010. Tuberculosiscontact investigation in lowprevalence countries: a Europeanconsensus. Eur Respir

Isma Yuniar, Sarwono, Susi Dwi Lestari, 2018, Hubungan Status Gizi Dan Pendapatan Terhadap Kejadian Tuberkulosis Paru, Jurnal Perawat Indonesia.

Kunoli, F. J, 2013, Pengantar Epidemiologi Penyakit Menular: Untuk Mahasiswa Kesehatan Masyarakat. Jakarta.

Kemenkes RI, 2011, Pedoman Nasional Pengendalian Tuberkulosis.

Kemenkes RI, Peraturan menteri Kesehatan Republik Indonesia nomor 1077/Menkes/Per/V/2011, Tentang pedoman Penyehatan Udara Dalam Ruang Rumah. 
Anakes: Jurnal Ilmiah Analis Kesehatan Vol. 7 No.1; Maret 2021 p-ISSN: 2088-5687 e:ISSN: 2745-6099

Kemenkes RI. 2017, Data dan Informasi Profil Kesehatan Indonesia 2017. Kementerian Kesehatan RI.

Rahmi Novita Yusuf dan Nurleli, 2018, Hubungan Status Gizi Dengan Kejadian Tb Paru, Jurnal Kesehatan Saintika Meditory.

Riskesdas. 2018, Hasil Utama Riskesdas. Kementerian Kesehatan.

World Health Organization. 2015. 'The End TB Strategy, World Health Organisation, Geneva.

World Health Organization. 2017. Global Tuberculosis Report. 